Check for updates

Cite this: RSC Adv., 2018, 8, 9202

Received 28th January 2018 Accepted 21st February 2018

DOI: $10.1039 / \mathrm{c} 8 \mathrm{ra00862k}$

rsc.li/rsc-advances

\section{The effect of co-sensitization methods between N719 and boron dipyrromethene triads on dye- sensitized solar cell performance $\uparrow$}

\author{
Sompit Wanwong, (D) *ab Weradesh Sangkhun (1D ${ }^{a}$ \\ and Jatuphorn Wootthikanokkhan ${ }^{\text {ab }}$
}

\begin{abstract}
A boron dipyrromethene (BODIPY) featuring triphenylamine triad, BD, has been synthesized as a cosensitizer in dye-sensitized solar cells (DSCs). The optical and electrochemical properties of BD have been characterized using UV-vis spectroscopy and cyclic voltammetry. DSCs containing co-sensitizers, N719 and BD, have been prepared in two procedures using co-deposition and stepwise deposition. The influences of the staining processes, co-deposition and stepwise deposition on dye loading, dye dispersion on a $\mathrm{TiO}_{2}$ photoanode and DSC performance have been investigated using FTIR, SEM-EDS, I$V$ test and IPCE measurement, respectively. We found that stepwise co-sensitization provided higher solar cell efficiency, compared to those stained with a co-deposition method. N719/5\% BD showed the highest power conversion efficiency of $5.14 \%$. Interestingly, the enhanced device efficiency was $66 \%$ higher than that of a device containing the single N719 dye.
\end{abstract}

\section{Introduction}

Dye-sensitized solar cells (DSCs) are one of the promising photovoltaic technologies due to their cheaper cost, thinner thickness, flexibility and easy fabrication as compared to silicon solar cells. ${ }^{1-3}$ Although dye-sensitized solar cells are still in the research phase, integration of DSCs within buildings or portable devices is capturing the community's interest. A typical DSC consists of a transparent electrode, dye-sensitizers adsorbed on $\mathrm{TiO}_{2}$ semiconductor, electrolyte and a counter electrode. DSC produces electricity by the following steps; (1) dyesensitizers absorb light and generate exited electrons, (2) the excited electrons transfer to the conduction band of $\mathrm{TiO}_{2}$ and further transport to the anode and (3) the oxidized dyes are regenerated by the iodide redox couple, while the positive charge transported to the cathode. ${ }^{\mathbf{1 , 2 , 4}}$ It is known that the dyesensitizer is essential to the performance of DSCs. Broad absorption of sun spectrum with high molar absorptivity and suitable energy levels of the dye-sensitizer are keys to obtain large amount of photon flux and efficient electron transporting to the $\mathrm{TiO}_{2}$ layer which influences on the overall efficiency of solar cells. ${ }^{1,5,6}$ Thus, many efforts have been focused on the

${ }^{a}$ Division of Materials Technology, School of Energy, Environment and Materials, King Mongkut's University of Technology Thonburi, Bangkok 10140, Thailand. E-mail: sompit.wan@kmutt.ac.th

${ }^{b}$ Nanotec-KMUTT Center of Excellence on Hybrid Nanomaterials for Alternative Energy, King Mongkut's University of Technology Thonburi, Bangkok 10140, Thailand $\uparrow$ Electronic supplementary information (ESI) available. See DOI: $10.1039 / \mathrm{c} 8 \mathrm{ra00862k}$ development of dye-sensitizers. The dye-sensitizers can be classified in two groups, the metal complex sensitizer and metal-free organic sensitizer. The first group consists of metal ions including $\mathrm{Ru}, \mathrm{Ni}$ and Co complex with bipyridine or terpyridine ligands and adsorbing group. ${ }^{1}$ The most famous classical dyes are N3, N719 and N749., ${ }^{4,5}$ Such dyes provided remarkable efficiency above $10 \%$ due to their wide absorption range that provide high $J_{\mathrm{sc}}$ value. However, absorption of metal complex sensitizers is not optimal because they inherently have moderate molar extinction coefficient at the long wavelength region which limit amount of photon harvesting. ${ }^{5,7,8}$ On the other hand, metal-free organic sensitizer possessing high molar extinction coefficient have gained considerable attention. Organic dye-sensitizers featuring donor-acceptor (D-A) molecular structures have been employed to broaden the light absorption properties. ${ }^{\mathbf{9 , 1 0}}$ Most of organic sensitizers are based on the triarylamine, carbazole, squaraine, boron dipyrromethene, porphyrin and phthalocyanine structures. ${ }^{\text {11-18 }}$ However, most of power conversion efficiency of DSCs containing organic sensitizers are still lower than those of Ru dyes.,

Alternative approach that could fulfill the drawback of using single dye sensitizer is co-sensitized titania by two or more dyes to achieve optimal absorption. In the multiple dyes system, the low absorption of $\mathrm{Ru}$ dye at the long wavelength will be complemented with the intense absorption of organic dye, resulting in panchromatic absorption and leading to enhance in device efficiency. ${ }^{2,5,10,19}$ For example, Han et al. ${ }^{20}$ developed a cisconfiguration squaraine dye (HSQ1) to co-sensitized with N3 dye. DSC based on HSQ1 + N3 showed improved $J_{\mathrm{sc}}$ and $V_{\mathrm{oc}}$ compared to those of DSC based on SQ1 + N3 due to broader 
IPCE spectrum and suppress aggregation of N3. Chen et al. ${ }^{21}$ synthesized porphyrin dye, denoted as HD18, and co-sensitized with $\mathbf{N 7 1 9}$ for the enhancement of the spectral response. The combination of these two sensitizers showed full color spectrum, resulting increasing of overall PCE. Recently, $\mathrm{Hu}$ et $a .^{22}$ reported that co-sensitization of polyphenylene with N719 can enhanced PCE due to the increase of light absorption and the retardation of electron recombination and dye aggregation. These examples of co-sensitized DSCs suggested that suitable structure of organic sensitizer should be considered to avoid aggregation among dyes on the $\mathrm{TiO}_{2}$ surface and retardation of electron recombination..$^{20-22}$

Despite the co-sensitization of Ru dyes with NIR organic dyes including porphyrins and squaraines have been reported, another interesting dye is boron dipyrromethene (BODIPY). BODIPY has gained recognition as a building block of NIR dye for using in organic solar cells (OSCs) and DSCs. ${ }^{16,23-29}$ The BODIPY with appropriate structural modification can provide tunable panchromatic absorption from $500-800 \mathrm{~nm} \cdot .^{29-33}$ In addition, DSC containing Ru dye and BODIPY sensitizer have been rarely reported. It was apparent from our previous study that $\mathrm{D}-\pi-\mathrm{A}-\pi-\mathrm{D}$ structure of the BODIPY containing ethynyl triphenylamine have effective electronic communication between the donor triphenylamine (TPA) and acceptor BODIPY via the ethynyl linker. ${ }^{34}$ As a result, the BODIPY triad exhibited broad absorption up to red edge region. Thus, the BODIPY triad is an attractive molecular platform to use as an organic cosensitizer to complement light absorption window of $\mathrm{Ru}$ sensitizer such as N719. In our molecular design as shown in Fig. 1. We reengineered the TPA-BODIPY-TPA by functionalized an cyanoacrylic acid anchoring group at the meso-position of the BODIPY core because theoretical studies reported that the meso-position of BODIPY unit is more suitable for electron injection to the $\mathrm{TiO}_{2}$ conduction band. ${ }^{16,31}$

We are noticed that similar BODIPY triad structures, distyryl triphenylamine-BODIPY, where triphenylamine units are functionalized on 3-and 5-position of BODIPY, have been reported by Akkaya et al. ${ }^{25}$ and Feng et al. ${ }^{35}$ However, the performance of DSC containing co-adsorbents, BODIPY and N719, has not been demonstrated. Here, we reported synthesis and characterizations of BD sensitizer. In addition, two procedures to cosensitized $\mathbf{N 7 1 9}$ with $\mathbf{B D}$ on $\mathrm{TiO}_{2}$ semiconductor is our interest. In the first procedure, N719 and BD were mixed together prior to co-deposit on the $\mathrm{TiO}_{2}$. In the second procedure, stepwise co-sensitization, N719 was first stained on the $\mathrm{TiO}_{2}$ layer, followed by immersion of $\mathbf{B D}$ on the sensitized $\mathrm{TiO}_{2}$.

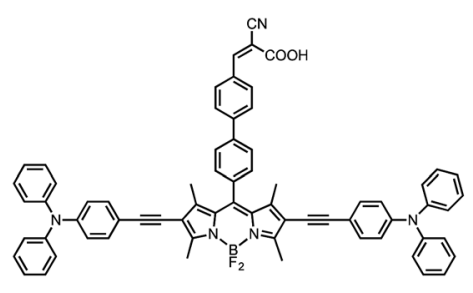

BD

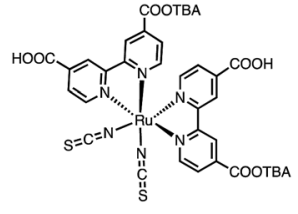

N719
Fig. 1 The molecular structure of BODIPY sensitizer (BD) and N719.
The DSCs efficiency were investigated and the influence of cosensitization procedures on photovoltaic parameters and device performance were discussed.

\section{Experimental sections}

\section{Instrumentations}

${ }^{1} \mathrm{H}-\mathrm{NMR},{ }^{13} \mathrm{C}$-NMR spectra were measured in $\mathrm{CDCl}_{3}$ and $\mathrm{MeOD}$ solution at $500 \mathrm{MHz}$, and $125 \mathrm{MHz}$, respectively, on Bruker NMR spectrometers. The chemical shifts of NMR spectra were recorded using the residual proton and carbon signal of the deuterated solvent as the internal standard. The spectra were reported in ppm, all $J$ values are in $\mathrm{Hz}$, and peak multiplicities are given, the following abbreviations are used: s, singlet; $d$, doublet; m, multiplet. The optical spectra of BD solution were recorded on a Thermo Scientific UV-Genesys 10s spectrophotometer and the solid state optical spectra of dye-sensitized on $\mathrm{TiO}_{2}$ film were recorded on a Cary 5000, Agilent Technologies UV-vis-NIR spectrophotometer. Cyclic voltammetric (CV) measurements were carried out on a Metrohm Autolab potentiostat with an electrochemical system utilizing a threeelectrode configuration consisting of a glassy carbon electrode, Pt electrode, a $\mathrm{Ag} / \mathrm{AgCl}$ electrode as working electrode, counter electrode and reference electrode, respectively. The cyclic voltammograms of BODIPYs were recorded in anhydrous $\mathrm{CH}_{2} \mathrm{Cl}_{2}$ with $0.1 \mathrm{M}$ tetrabutylammonium hexafluorophosphate $\left(\mathrm{TBAPF}_{6}\right)$ at a scan rate of $50 \mathrm{mV} \mathrm{s}^{-1}$. The voltammogram was normalized to half-wave potential of ferrocene/ferrocenium redox couple $\left(E_{1 / 2}(\mathrm{Fc} / \mathrm{Fc}+)\right)$ FTIR spectra were recorded on a Thermo Nicolet 6700 spectrometer. SEM micrograph was carried out using FEI Nova Nanosem 450. Energy dispersive Xray spectroscopy (EDS) was recorded on Bruker Nano XFlash $6 / 3$. The current density-voltage $(J-V)$ curved were measured using Keithley 2400 source-measurement unit and a Newport 91150V solar simulator. The incident photon-to-current conversion efficiency (IPCE) measurement was performed on Oriel instrument (OPS-A500) with Xe lamp and Oriel 3502 optical chopper to give a monochromatic light source.

\section{Materials}

4-Iodobenzyl-meso-BODIPY (compound 1) and 4-ethynyltriphenylamine were synthesized according to reported literature. ${ }^{34}$ 4-Formylphenylboronic acid pinacol ester, $\mathrm{N}$ iodosuccinimide, copper iodide, tetrakis(triphenylphosphine) palladium $(0)\left(\mathrm{Pd}\left(\mathrm{PPh}_{3}\right)_{4}\right)$, cyanoacetic acid were purchased from Aldrich. Anhydrous sodium sulfate, potassium carbonate, triethylamine, ammonium acetate, and glacial acetic acid were purchased from Fisher. HPLC grade dichloromethane, methanol, anhydrous $N, N^{\prime}$-dimethylformamide, toluene and acetonitrile were purchased from Fisher. For DSC fabrication materials, FTO glass, titanium isopropoxide (TTIP), anhydrous acetonitrile and tert-butanol were purchased from Aldrich. $\mathrm{TiO}_{2}$ (P25) was purchased from PlasmaChem, Germany. N719, HI-30 electrolyte and Pt paste were purchased from Solaronix. NMR solvents include deuterated chloroform $\left(\mathrm{CDCl}_{3}\right)$ and deuterated methanol (MeOD) were purchased from Cambridge Isotope 
Laboratories. Silica gel for column chromatography was purchased from Silicycle. All chemicals were used as received.

\section{Synthesis detail}

Synthesis of (1,1'-biphenyl)-4-carbaldehyde-meso-BODIPY, compound 2. 4-Iodobenzyl-meso-BODIPY ( $0.48 \mathrm{~g}, 1.0 \mathrm{mmol})$ and 4-formylphenylboronic acid pinacol ester ( $0.3 \mathrm{~g}, 1.2 \mathrm{mmol})$ were dissolved in toluene $(20 \mathrm{~mL})$. The solution was degassed with $\mathrm{N}_{2}$ for 10 minutes. $\mathrm{Pd}\left(\mathrm{PPh}_{3}\right)_{4}(0.1 \mathrm{~g}, 0.1 \mathrm{mmol})$ were added, followed by addition of $2 \mathrm{M} \mathrm{K}_{2} \mathrm{CO}_{3}(5 \mathrm{~mL})$. The reaction mixture was refluxed under $\mathrm{N}_{2}$ for 24 hours. The reaction mixture extracted with dichloromethane (DCM) and water. The organic layers were dried by sodium sulfate $\left(\mathrm{Na}_{2} \mathrm{SO}_{4}\right)$ and evaporated in vacuo. The crude mixture was purified by column chromatography on silica gel using DCM/hexane as an eluent to give the product 2 as orange solid $(0.25 \mathrm{~g}, 42 \%){ }^{1} \mathrm{H}-\mathrm{NMR}(500 \mathrm{MHz}$, $\left.\mathrm{CDCl}_{3}\right): \delta(\mathrm{ppm}), 10.09(\mathrm{~s}, 1 \mathrm{H}), 8.01(\mathrm{~d}, J=10 \mathrm{~Hz}, 2 \mathrm{H}), 7.86(\mathrm{~d}, J=$ $10 \mathrm{~Hz}, 2 \mathrm{H}$ ), 7.81 (d, $J=10 \mathrm{~Hz}, 2 \mathrm{H}), 7.42$ (d, $J=10 \mathrm{~Hz}, 2 \mathrm{H}), 6.00$ (s, 2H), 2.57 (s, 6H), $1.44(\mathrm{~s}, 6 \mathrm{H}){ }^{13} \mathrm{C}-\mathrm{NMR}\left(125 \mathrm{MHz}, \mathrm{CDCl}_{3}\right)$ : $\delta$ (ppm), 191.75, 155.75, 145.89, 142.97, 140.87, 140.27, 135.61, 135.29, 131.32, 130.35, 128.86, 127.93, 127.66, 121.36, 14.57 MALDI-TOF MS $(\mathrm{m} / \mathrm{z})$ calculated for $\mathrm{C}_{26} \mathrm{H}_{23} \mathrm{BF}_{2} \mathrm{~N}_{2} \mathrm{O}[\mathrm{M}+\mathrm{Na}]$, 451.1872; found 451.1889 .

Synthesis of ((1,1'-biphenyl)-4-carbaldehyde-meso-2,6diiodo-BODIPY), compound 3. Compound 2 ( $0.20 \mathrm{~g}, 0.46 \mathrm{mmol})$ was dissolved in DCM $(20 \mathrm{~mL})$ and then degassed with $\mathrm{N}_{2}$ for 5 minutes. A solution of $N$-iodosuccinimide (NIS) (0.42 g, 1.86 $\mathrm{mmol}$ ) in dimethylformamide (DMF) (4 mL) was added dropwise to the solution mixture. The reaction mixture was stirred under $\mathrm{N}_{2}$ at room temperature and was kept in the dark for 2 days. After that, the crude mixture was extracted with DCM and water. The organic phase was dried over $\mathrm{Na}_{2} \mathrm{SO}_{4}$ and concentrated in vacuo. The crude product was then purified by column chromatography over silica with DCM/hexane as an eluent to give the product 3 as red solid $(0.20 \mathrm{~g}, 63 \%){ }^{1} \mathrm{H}-\mathrm{NMR}(500 \mathrm{MHz}$, $\left.\mathrm{CDCl}_{3}\right): \delta(\mathrm{ppm}), 10.10(\mathrm{~s}, 1 \mathrm{H}), 8.02(\mathrm{~d}, J=5 \mathrm{~Hz}, 2 \mathrm{H}), 7.86(\mathrm{~d}, J=$ $5 \mathrm{~Hz}, 2 \mathrm{H}), 7.84(\mathrm{~d}, J=10 \mathrm{~Hz}, 2 \mathrm{H}), 7.40(\mathrm{~d}, J=10 \mathrm{~Hz}, 2 \mathrm{H}), 2.66$ (s, $6 \mathrm{H}), 1.46(\mathrm{~s}, 6 \mathrm{H}){ }^{13} \mathrm{C}-\mathrm{NMR}\left(125 \mathrm{MHz}, \mathrm{CDCl}_{3}\right): \delta(\mathrm{ppm}), 191.69$, 157.09, 145.57, 145.18, 140.91, 140.2, 135.77, 134.95, 131.21, 130.40, 128.71, 128.24, 127.72, 17.20, 16.06. MALDI-TOF MS (m/ $z$ ) calculated for $\mathrm{C}_{26} \mathrm{H}_{21} \mathrm{BF}_{2} \mathrm{I}_{2} \mathrm{~N}_{2} \mathrm{O}[\mathrm{M}+\mathrm{Na}]$, 679.9804; found 702.9674 .

Synthesis of (1,1'-biphenyl)-4-carbaldehyde-meso-2,6bis(ethynyltriphenylamine)-BODIPY, compound 4. Compound $3(0.20 \mathrm{~g}, 0.29 \mathrm{mmol})$ was dissolved in dry toluene $(20 \mathrm{~mL})$. The reaction mixture was purged with $\mathrm{N}_{2}$ for 15 minutes. $\mathrm{Pd}\left(\mathrm{PPh}_{3}\right)_{4}$ (0.03 g, $0.03 \mathrm{mmol}$ ) and copper iodide (CuI) (0.005 g, $0.03 \mathrm{mmol})$ were added, followed by addition of 4-ethynyltriphenylamine $(0.3 \mathrm{~g}, 1 \mathrm{mmol})$. The reaction mixture was stirred at room temperature for 15 minutes, followed by addition of $\mathrm{Et}_{3} \mathrm{~N}$ $(2 \mathrm{~mL})$. The reaction mixture was refluxed under $\mathrm{N}_{2}$ protection for 36 hours. The mixture was filtered with Celite and the solvent was removed using rotary evaporator. The reaction mixture was poured with $50 \mathrm{~mL}$ of water and extracted with DCM. The combined organic layers were dried over sodium sulfate and concentrated under reduced pressure to afford the crude mixture. The residue was then purified by column chromatography over silica gel with DCM/hexane as an eluent to provide the product 4 as deep blue solid (0.11 g, 36\%) ${ }^{1} \mathrm{H}-\mathrm{NMR}$ $\left(500 \mathrm{MHz}, \mathrm{CDCl}_{3}\right): \delta(\mathrm{ppm}), 10.10(\mathrm{~s}, 1 \mathrm{H}), 8.02(\mathrm{~d}, J=5 \mathrm{~Hz}, 2 \mathrm{H})$, 7.88 (d, $J=5 \mathrm{~Hz}, 2 \mathrm{H}), 7.85$ (d, $J=10 \mathrm{~Hz}, 2 \mathrm{H}), 7.44$ (d, $J=10 \mathrm{~Hz}$, 2H), 7.30-7.24 (m, 9H), 7.10-6.97 (m, 19H), $2.72(\mathrm{~s}, 6 \mathrm{H}), 1.57$ (s, $6 \mathrm{H}){ }^{13} \mathrm{C}-\mathrm{NMR}\left(125 \mathrm{MHz}, \mathrm{CDCl}_{3}\right): \delta(\mathrm{ppm})$ 191.73, 158.58, 147.86, $147.13,145.73,143.19,141.21$, 120.63, 132.25, 130.38, 129.36, $128.81,128.08,127.71,124.89,123.53,122.35,116.12,96.86$, $80.61,13.72$, 13.59. MALDI-TOF MS $(\mathrm{m} / \mathrm{z})$ calculated for $\mathrm{C}_{66} \mathrm{H}_{49} \mathrm{BF}_{2} \mathrm{~N}_{4} \mathrm{O}[\mathrm{M}+\mathrm{Na}]$ 985.3967; found 985.3943.

Synthesis of $\left(\left[1,1^{\prime}\right.\right.$-biphenyl $]-4-y l-2$-cyanoacrylic acid-meso2,6-bis(ethynyltriphenylamine)-BODIPY), compound 5 (BD). Compound 4 ( $0.07 \mathrm{~g}, 0.07 \mathrm{mmol})$ was dissolved in chloroform $(10 \mathrm{~mL})$ and acetic acid $(3 \mathrm{~mL})$. Cyanoacetic acid $(0.02 \mathrm{~g}, 0.57$ $\mathrm{mmol})$ and ammonium acetate $(0.02 \mathrm{~g}, 0.057 \mathrm{mmol})$ were added to a solution. The reaction mixture was refluxed under $\mathrm{N}_{2}$ atmosphere for 12 hours and then was allowed to cool at room temperature. After that, water $(15 \mathrm{~mL})$ was added to the crude mixture, followed by extraction with $\mathrm{CHCl}_{3}$. The organic layers were dried over sodium sulfate. The crude product was concentrated under reduced pressure and was purified on silica gel using $\mathrm{MeOH}$ and $\mathrm{CHCl}_{3}$ as eluents. The dark blue powder was obtained as product 5, BD $(0.04 \mathrm{~g}, 55 \%){ }^{1} \mathrm{H}-\mathrm{NMR}(500 \mathrm{MHz}$, $\left.\mathrm{CDCl}_{3} / \mathrm{MeOD}\right): \delta(\mathrm{ppm}), 8.24(\mathrm{~s}, 1 \mathrm{H}), 8.05(\mathrm{~d}, 2 \mathrm{H}), 7.82(\mathrm{~m}, 4 \mathrm{H})$, 7.38 (d, 2H), 7.32-6.92 (m, 28H), $2.64(\mathrm{~s}, 6 \mathrm{H}), 1.53(\mathrm{~s}, 6 \mathrm{H}){ }^{13} \mathrm{C}-$ NMR (125 MHz, $\left.\mathrm{CDCl}_{3} / \mathrm{MeOD}\right): \delta$ (ppm), 158.71, 148.24, $147.45,144.16,143.69,141.85$, 140.93, 134.87, 132.52, 131.70, $131.44,129.65,129.11,128.24,127.99,125.21,123.86,122.57$, 116.99, 116.35, 97.27, 80.79, 13.80 MALDI-TOF MS $(\mathrm{m} / \mathrm{z})$ calculated for $\mathrm{C}_{69} \mathrm{H}_{50} \mathrm{BF}_{2} \mathrm{~N}_{5} \mathrm{O}_{2}[\mathrm{M}+\mathrm{H}], 1029.4026$ found 1030.4116 .

\section{Device fabrication and photovoltaic measurements}

To fabricate the dye-sensitized solar cells device, the $\mathrm{TiO}_{2}$ electrodes were prepared following the previous reported procedure. ${ }^{36}$ In brief, the FTO glass sheet $\left(\sim 7 \Omega \mathrm{cm}^{-2}\right)$ was cut into $2.5 \times 2.5 \mathrm{~cm}^{2}$. FTO glass plates were pretreated with $0.2 \mathrm{M}$ $\mathrm{HCl}$ in an ultrasonic bath for $15 \mathrm{~min}$, followed by washing with DI water under sonication for $10 \mathrm{~min}$, twice. After that, the FTO substrates were sonicated with isopropanol (IPA) for $20 \mathrm{~min}$ and then dried by purging with $\mathrm{N}_{2}$ gas. Then, $\mathrm{TiO}_{x}$ sol-gel $(10 \mu \mathrm{L})$ was coated on the FTO plates using the rapid convection deposition technique with a deposition rate of $600 \mu \mathrm{m} \mathrm{s}^{-1}$. The $\mathrm{TiO}_{x}$ layer was then gradually heated under air atmosphere at $500{ }^{\circ} \mathrm{C}$ for $1 \mathrm{~h}$ with a heating rate of $10{ }^{\circ} \mathrm{C} \mathrm{min}{ }^{-1}$. After that, the doctor blade technique was used to deposit a mesoporous layer of $\mathrm{TiO}_{2}$, a mixture of $0.10 \mathrm{~g}$ of $\mathrm{TiO}_{2}$ (P25) in $0.429 \mu \mathrm{L}$ of IPA and $10 \mu \mathrm{L}$ of titanium isopropoxide (TTIP). Subsequently, $\mathrm{TiO}_{2}$ paste was sintered at $500{ }^{\circ} \mathrm{C}$ for $1 \mathrm{~h}\left(10{ }^{\circ} \mathrm{C} \mathrm{min}{ }^{-1}\right)$. Dye solutions of BD $(0.39 \mathrm{mM})$ and $\mathbf{N 7 1 9}(0.33 \mathrm{mM})$ in acetonitrile/tert-butanol $(1: 1$ $\mathrm{v} / \mathrm{v}$ ) have been prepared. The co-sensitized of N719 with BD have been prepared in two methods. The first method, co-deposition, solutions of N719 and BD have been mixed by varied BD concentration as $5 \%$ and $10 \%$, respectively. The $\mathrm{TiO}_{2}$ photoanodes were immersed into dye solutions and stored at $80{ }^{\circ} \mathrm{C}$ for $4 \mathrm{~h}$. The dye stained electrodes were rinsed with acetonitrile 
several times and dried at $80{ }^{\circ} \mathrm{C}$ for $30 \mathrm{~min}$. For the second method, the stepwise deposition, the prepared $\mathrm{TiO}_{2}$ electrodes were immersed in $0.33 \mathrm{mmol}$ of $\mathbf{N 7 1 9}$ solution in acetonitrile/ tert-butanol $(1: 1 \mathrm{v} / \mathrm{v})$ at $80{ }^{\circ} \mathrm{C}$ for $4 \mathrm{~h}$ and then rinsed with anhydrous acetonitrile for several times. After that, the sensitized photoanodes were dried at $80^{\circ} \mathrm{C}$ for 30 minutes to remove the remaining solvent. The sensitized $\mathrm{TiO}_{2}$ was then coated with BD by dipping in $5 \%$ and $10 \%$ of BD solutions, respectively, at $80{ }^{\circ} \mathrm{C}$ for another $1 \mathrm{~h}$. Finally, the sensitized films were rinsed with acetonitrile and then dried at $80^{\circ} \mathrm{C}$ for $30 \mathrm{~min}$. Counter electrodes were prepared by coating platinum (Pt) paste on drilled and cleaned FTO glass plates using doctor blade technique and then calcined at $450{ }^{\circ} \mathrm{C}$ for $1 \mathrm{~h}$ with a heating rate of $10{ }^{\circ} \mathrm{C} \mathrm{min}^{-1}$. The Pt counter electrode and the dye-sensitize electrode were sandwiched together using Surlyn film as the frame. The gap between electrodes was sealed by melting the Surlyn film. Next, $10 \mu \mathrm{L}$ of electrolyte solution consisting of iodide/triiodide, HI-30, was injected through the drilled holes on counter electrode. Finally, the holes were sealed with the Kapton tape to prevent the leakage of liquid electrolyte. The active cell area of DSCs was fixed to be 0.40 $\mathrm{cm}^{2}$. The DSC performance was characterized using the current density-voltage $(J-V)$ plots. The photo current was measured under AM 1.5G illumination $100 \mathrm{~mW} \mathrm{~cm}^{-2}$. The light intensity was calibrated with reference monocrystalline silicon cell.

\section{Dye loading measurement}

The adsorption amount of single dye and mixed dyes have been measured following procedure report in literatures. ${ }^{37,38}$ Briefly, N719 on $\mathrm{TiO}_{2}$ layer was desorbed using $0.1 \mathrm{M}$ of $\mathrm{NaOH}$ in EtOH/ $\mathrm{H}_{2} \mathrm{O}(1: 1 \mathrm{v} / \mathrm{v})$. Then, BD was extracted using $\mathrm{CHCl}_{3} / \mathrm{MeOH}(1: 1$ $\mathrm{v} / \mathrm{v})$. The UV-vis spectrum of each sample solution was compared with the known concentration of N719 and BD. The dye loading was determined using Beer's law.

\section{Results and discussion}

\section{Synthesis}

The BODIPY sensitizer was synthesized according to the synthesis protocol depicted in Scheme 1. The precursor iodoBODIPY (1) was prepared following the procedure in our recent study. ${ }^{34}$ BODIPY (1) was coupled with 4-formylphenylboronic acid pinacol ester to yield (1,1'-biphenyl)-4carbaldehyde-meso-BODIPY (2). Then iodination at the 2 and 6 positions of BODIPY core provided 2,6-diiodo-BODIPY (3) in a good yield of $63 \%$. Next, compound 3 was coupled with 4 ethynyltriphenylamine using Sonogashira cross coupling reaction to provide corresponding TPA- $\equiv-$ BODIPY- $\equiv-$ TPA (4) in $36 \%$ yield. Finally, the desired BODIPY sensitizers, BD, was obtained by Knoevenagel condensation between the aldehyde moiety of $\mathbf{4}$ with cyanoacetic acid. All compounds were purified by column chromatography. The molecular structures were confirmed using NMR spectroscopy and mass spectrometry. The ${ }^{1} \mathrm{H}$-NMR spectrum of 4 showed corresponding aldehyde proton at $10.09 \mathrm{ppm}$, aromatic protons of triphenylamine rings at 7.30-6.97 ppm. The spectrum of BD showed vinylic proton at $8.24 \mathrm{ppm}$, indicating that aldehyde was successfully converted to cyanoacrylate acid. This also confirm with mass spectrometry (see ESI†).

\section{Optical properties of BD}

Absorption spectra of BD in solution and in solid are shown in Fig. 2. The optical parameters including absorption maxima, molar extinction coefficient and absorption onset were summarized in Table 1. The blue solution of BD dye exhibited broad absorption in the range of 300-700 $\mathrm{nm}$. The two intense absorption bands at 345 and $598 \mathrm{~nm}$ are attributed to $\pi-\pi^{*}$ transition of the triphenylamine unit and the internal charge transfer (ICT) transition from the triphenylamine donor to the BODIPY unit. The molar extinction coefficient $(\varepsilon)$ of the lower

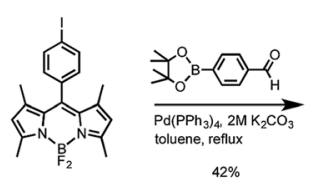

1

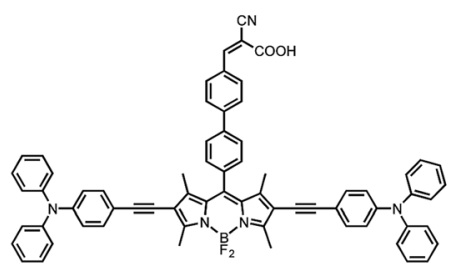

BD

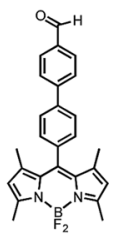

2

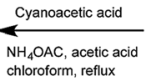

$55 \%$

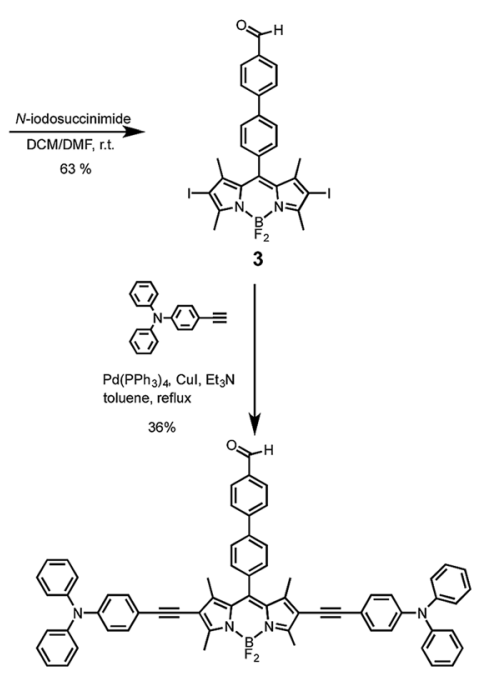

4

Scheme 1 Synthetic route of BODIPY (BD) sensitizer. 


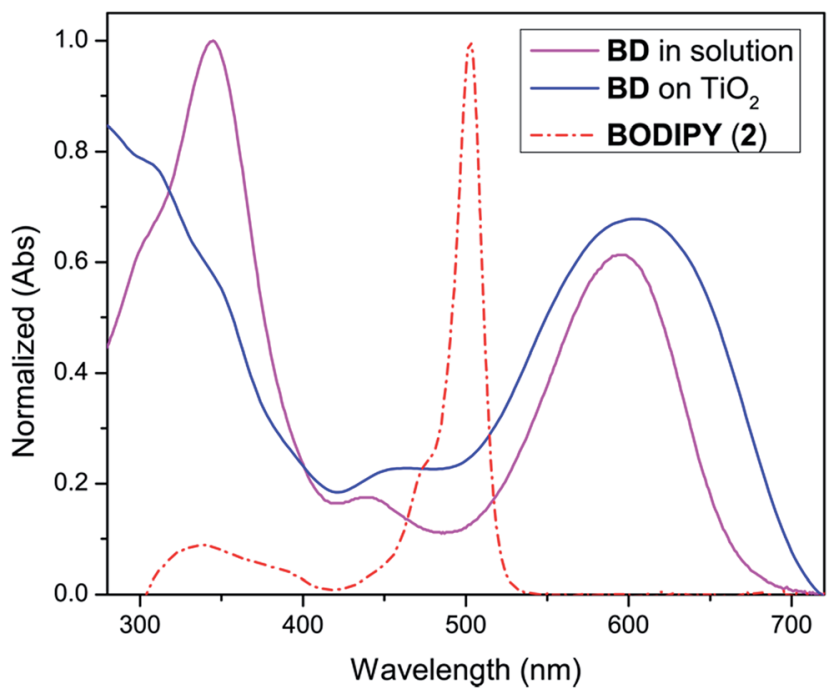

Fig. 2 Normalized UV-vis of BD in dichloromethane (pink) and adsorbed on $\mathrm{TiO}_{2}$ film (blue) and the BODIPY core (3) (red).

energy band was calculated to be $5.4 \times 10^{5} \mathrm{M}^{-1} \mathrm{~cm}^{-1}$. This high value would benefit to photon harvesting process. The onset wavelength was at $700 \mathrm{~nm}$, indicating red absorption with the optical energy bandgap of $1.77 \mathrm{eV}$. When BD was adsorbed onto a transparent $\mathrm{TiO}_{2}$ electrode, $\lambda_{\max }$ was shifted from $598 \mathrm{~nm}$ in solution to $606 \mathrm{~nm}$ on $\mathrm{TiO}_{2}$. The bathochromic shift is due to greater electronic interaction between the dye and $\mathrm{TiO}_{2}$ surface. ${ }^{14}$

\section{Electrochemical characterization of BD}

To evaluate the feasibilities of electron injection and dye regeneration process, the electrochemical properties of $\mathbf{B D}$ including redox properties, HOMO and LUMO of BD were investigated by cyclic voltammetry. The voltammogram of $\mathbf{B D}$ is shown in Fig. 3 and the electrochemical data are summarized in Table 2. As seen in Fig. 3, BD exhibited the low oxidation potential of $0.53 \mathrm{eV}$ due to the electron rich nature of triphenylamine moiety. This corresponds to the HOMO energy of $-5.33 \mathrm{eV}$ which is lower than the redox potential of triiodide redox couple $(-4.90 \mathrm{eV})$, and thus facilitated electron transfer from $\mathrm{I}^{-}$to the $\mathbf{B D}$ in dye regeneration process. A reduction potential of BD was approximately $-1.10 \mathrm{eV}$ and was calculated to be $-3.70 \mathrm{eV}$ of LUMO energy level. The LUMO level of BD $(-3.70 \mathrm{eV})$ is higher than that of the conduction band edge of $\mathrm{TiO}_{2}(-4.20 \mathrm{eV})$ and the difference is $0.5 \mathrm{eV}$. Therefore, excited electron from $\mathbf{B D}$ can be thermodynamically injected to the conduction band of $\mathrm{TiO}_{2}$.

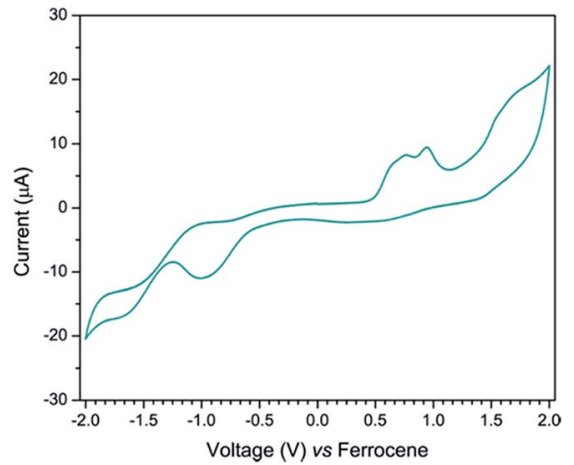

Fig. 3 Cyclic voltammogram of BD

Table 2 Summary of electrochemical data of BD

\begin{tabular}{llllll}
\hline Dye & $E_{\text {ox }}{ }^{a}(\mathrm{~V})$ & $\mathrm{HOMO}^{b}(\mathrm{eV})$ & $E_{\text {red }}{ }^{a}(\mathrm{~V})$ & $\operatorname{LUMO}^{b}(\mathrm{eV})$ & $E_{\text {g,elec }}{ }^{c}(\mathrm{eV})$ \\
\hline BD & +0.53 & -5.33 & -1.10 & -3.70 & 1.63
\end{tabular}

${ }^{a}$ The oxidation and reduction potentials were approximated from the oxidation and reduction peaks. ${ }^{b}$ The HOMO and LUMO energy levels were calculated using the following relationship; HOMO $=-\left(E_{\text {ox,onset }}\right.$ $+4.8) \mathrm{eV}$ and LUMO $=-\left(E_{\text {red,onset }}+4.8\right) \mathrm{eV} \cdot{ }^{39}{ }^{c} E_{\mathrm{g} \text {,elec }}=E_{\mathrm{LUMO}}-E_{\mathrm{HOMO}}$.

\section{FTIR characterization}

FTIR measurements have been conducted to investigate interaction of individual dyes (BD and N719) and co-sensitized dye on $\mathrm{TiO}_{2}$ film. From Fig. 4a, BD and $\mathbf{N 7 1 9}$ exhibited strong peak around $1700 \mathrm{~cm}^{-1}$ that correlate to $\mathrm{C}=\mathrm{O}$ stretching of the carbonyl group. The peaks at $1593 \mathrm{~cm}^{-1}$ and $1317 \mathrm{~cm}^{-1}$ represent asymmetric and symmetric vibration of carboxylate $\left(-\mathrm{COO}^{-}\right)$, respectively. The carboxylic peak of $\mathbf{B D}$ was higher than those of carboxylate peaks, suggesting that large amount of $\mathbf{B D}$ was not bound to the $\mathrm{TiO}_{2}$ surface.

FTIR-spectra of different co-dyeing process were depicted in Fig. 4 b, coding as $\mathbf{N 7 1 9}+5 \%$ BD and $\mathbf{N 7 1 9}+10 \%$ BD, were prepared via co-deposition method. While sample coding as $\mathbf{N} 719 / 5 \%$ BD and $\mathbf{N} 719 / 10 \%$ BD were prepared via stepwise procedure. FTIR-spectra of different co-dyeing process were depicted in Fig. 4b. The two strong bands at $1605 \mathrm{~cm}^{-1}$ and $1375 \mathrm{~cm}^{-1}$ were assigned to $\nu \mathrm{COO}_{\text {asym }}{ }^{-}$and $\nu \mathrm{COO}_{\text {sym }}{ }^{-}$, respectively. ${ }^{40}$ The difference $(\Delta \nu)$ of $\nu \mathrm{COO}_{\text {asym }}{ }^{-}$and $\nu \mathrm{COO}_{\text {sym }}{ }^{-}$ was $230 \mathrm{~cm}^{-1}$, suggesting the bidentate chelating binding of N719 to the $\mathrm{TiO}_{2}$ surface. ${ }^{41,42}$ The intensity of those two peaks were about the same, suggesting that the total dye molecules adsorbed on the $\mathrm{TiO}_{2}$ surface were similar. The peak at $2103 \mathrm{~cm}^{-1}$ was assigned to the $\mathrm{N}=\mathrm{C}$ vibration mode from the NCS group of N719. Interestingly, we observed that NCS peak of

Table 1 Summary of optical absorption maxima (solution and solid state), absorption coefficients, absorption onset, absorption maxima and the optical bandgaps of BD

\begin{tabular}{llllll}
\hline Dye & $\lambda_{\max }$ (solution) $(\mathrm{nm})$ & $\varepsilon_{\max }\left(\times 10^{5} \mathrm{M}^{-1} \mathrm{~cm}^{-1}\right)$ & $\lambda_{\max }\left(\mathrm{on} \mathrm{TiO}_{2}\right)(\mathrm{nm})$ & $\lambda_{\text {onset }}(\mathrm{solution})(\mathrm{nm})$ & $E_{\mathrm{g}, \text { opt }}(\mathrm{eV})$ \\
\hline BD & 345,598 & $8.7,5.4$ & 606 & 700
\end{tabular}




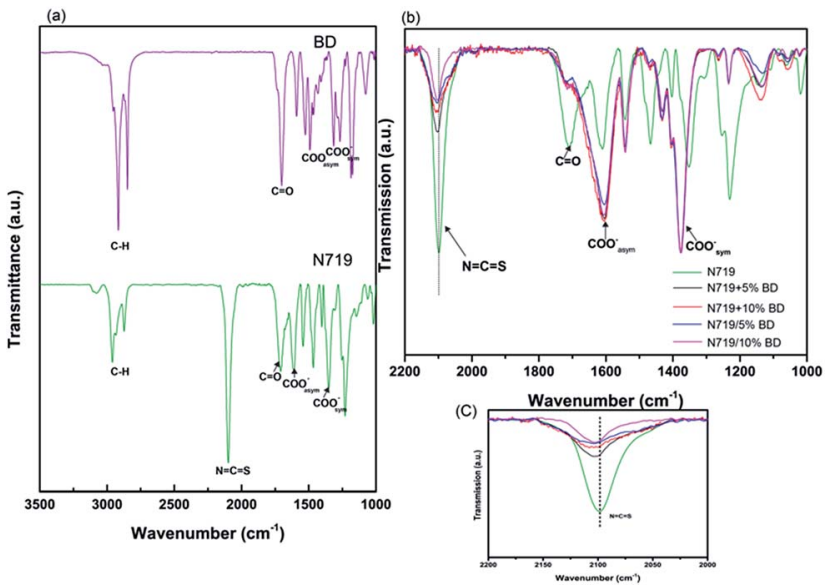

Fig. 4 FTIR Spectra (a) BD and N719 (b) co-sensitized N719 + BD on $\mathrm{TiO}_{2}$ film and (c) expansion of $\mathrm{N}=\mathrm{C}=\mathrm{S}$ bands.

co-sensitized N719 and BD was slightly shifted to 2117$2121 \mathrm{~cm}^{-1}$ and the peak intensity was decreased, as compared to $\mathbf{N 7 1 9}$ (Fig. 4c). This could be due to the different binding mechanism of N719 in which NCS interact to the $\mathrm{TiO}_{2}$ surface. This was also suggested from previous studies by Singh et al. ${ }^{42}$ and Johansson et al. $^{\mathbf{4 3}}$

\section{Dye loading}

Since N719 and BD have different molecular structure and number of anchoring group, we studied the dye loading capability and change of composition in different co-sensitization process. The adsorption amount of dyes has shown in Fig. 5. The BD cell exhibited dye loading amount of $1556.2 \mathrm{nmol} \mathrm{cm}^{-2}$, while the N719 cell showed considerable lower dye up-taking

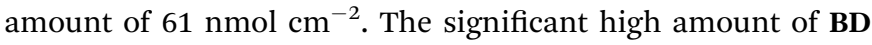
was due to aggregation of dye on $\mathrm{TiO}_{2}$ layer as we observed free carboxylic peak in FTIR result. For co-dyeing, N719 + 5\% BD and $\mathbf{N 7 1 9}+10 \%$ BD, as the BD concentration increased, the amount of BD was increased from $65 \mathrm{nmol} \mathrm{cm}{ }^{-2}$ to $140 \mathrm{nmol} \mathrm{cm}{ }^{-2}$. However, the amount of $\mathbf{N 7 1 9}$ was fixed to $43.2 \mathrm{nmol} \mathrm{cm}{ }^{-2}$. This

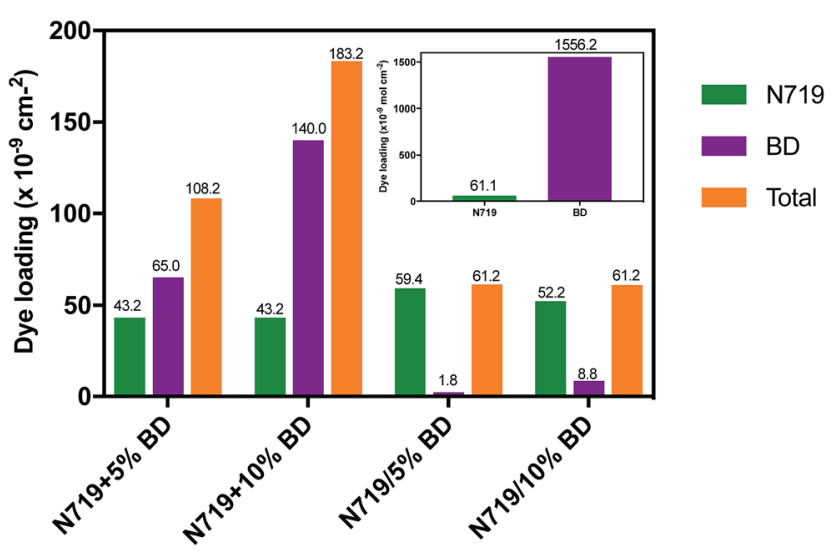

Fig. 5 Dye loading of individual BD and N719 cells and co-sensitize cells using co-deposition and stepwise deposition method.

indicated the competitive adsorption between BD and N719 on the limited sites of $\mathrm{TiO}_{2}$ surface. For the stepwise deposition, in which the photoanode was immersed in N719 solution, then dipped in BD solution, we found that the BD contents were significantly decreased to 1.8 and $8.8 \mathrm{nmol} \mathrm{cm}{ }^{-2}$, respectively. The total dye loading of the stepwise staining system was about $61 \mathrm{nmol} \mathrm{cm}{ }^{-2}$, that was similar to the individual N719.

In addition, SEM-EDS has been conducted to investigate the assemble morphology and chemical composition of cosensitized DSCs. SEM cross-sectional image of co-sensitized $\mathrm{TiO}_{2}$ on FTO glass and energy dispersive X-ray spectroscopy analysis (EDS) were illustrated in Fig. 6. The SEM cross sectional image of co-sensitized $\mathrm{TiO}_{2}$ on FTO glass has shown in Fig. 6a. EDS measurement has been conducted to investigate N719 and BD distribution on the $\mathrm{TiO}_{2}$ layer. The ruthenium (Ru) and fluorine (F) signals have been selected to qualitatively analyzed N719 and BD distribution in the $\mathrm{TiO}_{2}$ matrix. As seen from Fig. $6 \mathrm{~b}-\mathrm{g}$, the mapping images confirmed successful sensitization of N719 and BD. The device prepared from the co-dyeing process exhibited much higher signal intensity of $\mathrm{F}$ signal (cyan color) than the stepwise dyeing method. This implied high BD dispersion on $\mathrm{TiO}_{2}$ layer which was consistent to the dye loading result.

\section{Photovoltaic performance}

DSCs containing BD, N719 and co-sensitization of N719 and BD were fabricated. The current density versus voltage $(J-V)$ characteristic curves were presented in Fig. 7. The photovoltaic parameters of DSCs including photocurrent density $\left(J_{\mathrm{sc}}\right)$, open circuit voltage $\left(V_{\mathrm{oc}}\right)$, fill factor $(\mathrm{FF})$ and power conversion efficiency (PCE) were summarized in Table 3. Photovoltaic performance based on DSC containing BD showed a $J_{\mathrm{sc}}$ of $1.26 \mathrm{~mA} \mathrm{~cm}^{-2}$, a $V_{\mathrm{oc}}$ of $550 \mathrm{mV}$ and an $\mathrm{FF}$ of 0.64 , resulting in power conversion efficiency (PCE) of $0.45 \%$. The poor performance is caused by low $J_{\mathrm{sc}}$ and $V_{\mathrm{oc}}$ values. This caused by aggregation of $\mathbf{B D}$ on the $\mathrm{TiO}_{2}$ surface that increased charge

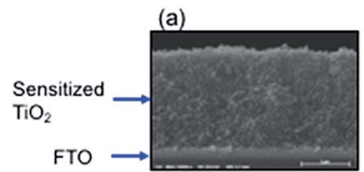

(d)

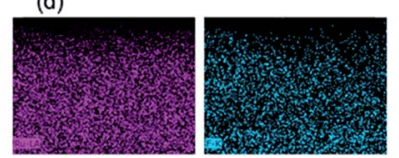

$\mathrm{N} 719+5 \% \mathrm{BD}$

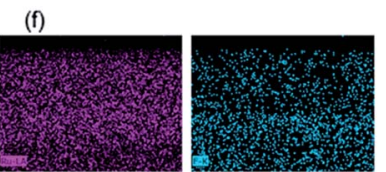

N719+10\%BD (b)

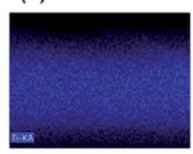

(e)

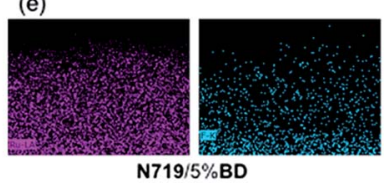

(g)

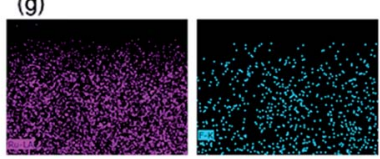

N719/10\%BD

(c)

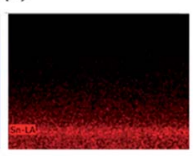

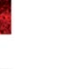




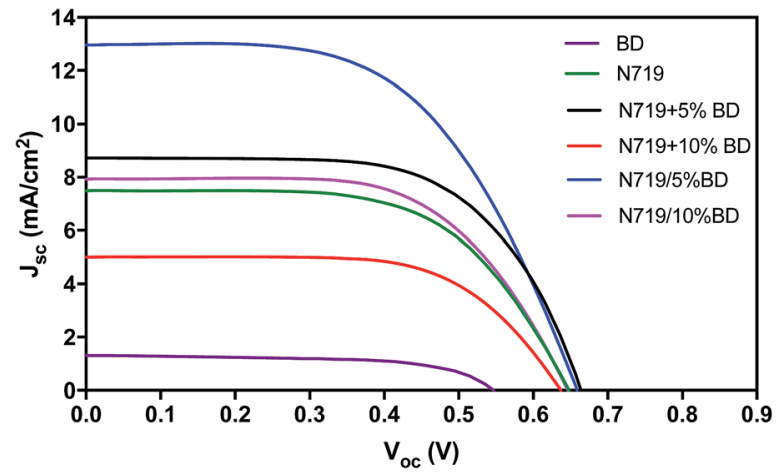

Fig. $7 \mathrm{~J}-\mathrm{V}$ characteristics of DSCs containing BD, N719 and cosensitized N719 + BD solar cells.

recombination and reduced electron injection to the $\mathrm{TiO}_{2}$ electrode. ${ }^{4-46}$ The DSC containing standard N719 sensitizer exhibited the $J_{\mathrm{sc}}$ of $7.09 \mathrm{~mA} \mathrm{~cm}{ }^{-2}$, a $V_{\mathrm{oc}}$ of $640 \mathrm{mV}$ and an $\mathrm{FF}$ of 0.67 , yielding PCE of $3.09 \%$. We noticed that this is considered low PCE as compared to some report in the literatures. This could be attributed to variation of layer thickness, active area and types of electrolyte and electrode materials.

Next, we prepared co-sensitized N719 and BD DSCs using co-deposition method. The PCE of N719 + 5\% BD and N719 + $10 \%$ BD were $3.85 \%$ and $2.01 \%$, respectively (Table 3 ). The efficiency of $\mathbf{N} 719+5 \%$ BD was raised by $24.6 \%$ in comparison with that of $\mathbf{N} 719(\mathrm{PCE}=3.09 \%)$. The enhanced efficiency was due to the increase of $J_{\mathrm{sc}}$ and $V_{\mathrm{oc}}$. However, we found that when increase concentration of BD to $10 \%(\mathbf{N 7 1 9}+10 \%$ BD $)$, the $J_{\mathrm{sc}}$ was declined to $5.02 \mathrm{~mA} \mathrm{~cm} \mathrm{c}^{-2}$, resulting in PCE of $2.01 \%$. The decreased efficiency could be correlate to higher amount of BD that accumulate on the $\mathrm{TiO}_{2}$ layer. This aggregation could trap free electrons travelling to the conduction band of $\mathrm{TiO}_{2}$. Interestingly, for stepwise sensitization DSCs, all devices have higher PCE compared to those of co-deposition DSCs as depicted in Fig. 5. PCEs of 5.14\% and $3.24 \%$ were obtained from $\mathbf{N} 719 / 5 \%$ BD and $\mathbf{N 7 1 9} / 10 \%$ BD, respectively. In addition, the trend of PCE was similar to the co-deposition DSCs in which N719/5\% BD > N719/10\% BD. The PCE of N719/5\% BD exhibited a $J_{\mathrm{sc}}$ of $12.98 \mathrm{~mA} \mathrm{~cm}^{-2}$, a $V_{\mathrm{oc}}$ of $660 \mathrm{mV}$ and an $\mathrm{FF}$ of 0.6 , corresponding to overall the best efficiency of $5.14 \%$. This showed an improvement of $66 \%$
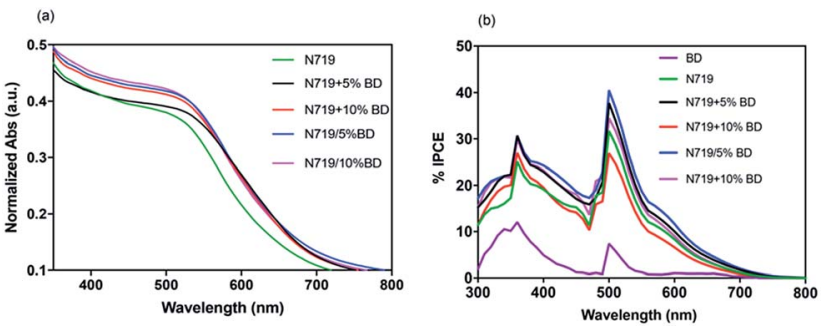

Fig. 8 (a) UV-vis absorption spectra of dye adsorbed on $\mathrm{TiO}_{2}$ films and (b) IPCE spectra BD, N719 and co-sensitized N719 + BD solar cells.

compared to the device sensitized with $\mathbf{N 7 1 9}$ and enhancement of $33 \%$ compared to the N719 $+5 \%$ BD using codeposition method. The increased PCE is corresponding to much higher $\left(J_{\mathrm{sc}}\right)$ from $7.09 \mathrm{~mA} \mathrm{~cm}{ }^{-2}$ of $\mathrm{N} 719$ cell to $12.98 \mathrm{~mA} \mathrm{~cm}^{-2}$.

To gain further insight into the attribution of BD and the cosensitization methods on light harvesting and photocurrent generation, UV-vis absorption spectroscopy of sensitized $\mathrm{TiO}_{2}$ film and IPCE measurements have been conducted. It can be seen from Fig. 8a that co-adsorption of BD and N719 films have red-shifted absorption and could compensate the absorption of N719, at the range of 500-700 nm. Next, we performed IPCE experiment using $300 \mathrm{~W}$ Xe lamp with low-speed chopper to provide chromatic lights from $300-800 \mathrm{~nm}$ and measuring $J_{\mathrm{sc}}$. From Fig. 8b, IPCE spectrum of BD was covered in the range of $300-550 \mathrm{~nm}$ with the lowest IPCE value of $10 \%$. For the mixed dye system, the IPCE spectra were covered in broader range from $300-700 \mathrm{~nm}$. The co-deposition devices exhibited the maximum value of IPCE as high as $37.8 \%$ and $26.91 \%$ for $\mathbf{N 7 1 9}$ $+5 \%$ BD and N719 + 10\% BD, respectively. On the other hand, the stepwise sensitized devices, N719/5\% BD and N719/10\% BD, exhibited higher IPCE of $40.5 \%$ and $34.4 \%$ at $500 \mathrm{~nm}$. The trend and increasing of IPCE values are in good agreement with $J_{\text {sc }}$ results. It is worth noting that although stepwise dyeing cells contain less BD amount, it can be able to enhance the IPCE value. Although we do not fully understand the reason for greater $J_{\mathrm{sc}}$ values of stepwise co-sensitization, we assume that this may be due to cascade electron transfer from BD to N719 to titania since BD has higher LUMO energy level $(-3.7 \mathrm{eV})$ than that of $\mathbf{N} 719(-3.9 \mathrm{eV}) .^{47,48}$

Table 3 Photovoltaic performance of DSCs based on BD, N719 and co-sensitized N719 with BD ${ }^{a}$

\begin{tabular}{|c|c|c|c|c|c|c|c|}
\hline BD & & & 1556.2 & 1.26 & 0.55 & 0.64 & 0.45 \\
\hline $\mathrm{N} 719+5 \% \mathrm{BD}$ & Co-deposition & 43.2 & 65.0 & 8.71 & 0.67 & 0.66 & 3.85 \\
\hline $\mathbf{N} 719+10 \% \mathbf{B D}$ & & 43.2 & 140 & 5.02 & 0.64 & 0.66 & 2.10 \\
\hline N719/5\% BD & Stepwise deposition & 59.4 & 1.8 & 12.98 & 0.66 & 0.60 & 5.14 \\
\hline
\end{tabular}

${ }^{a}$ Light source: $100 \mathrm{~mW} \mathrm{~cm}{ }^{-2}$, AM $1.5 \mathrm{G}$ simulated solar light; working area: $0.4 \mathrm{~cm}^{2}$. 


\section{Conclusions}

In summary, BD was synthesized and used as co-adsorbent with N719 for DSC application. The influence of co-sensitization procedures, co-deposition and stepwise deposition, on DSC performance have been investigated. We found that small amount of BD sensitizer in co-deposition and stepwise deposition bear a positive influence on device efficiency. The stepwise deposition significantly increase $J_{\text {sc }}$ values, resulting in higher PCEs. This is due to the improvement of IPCE and spectral response region at 500-700 $\mathrm{nm}$. The best cell was achieved from N719/5\% BD with PCE of 5.14\%.

\section{Conflicts of interest}

There are no conflicts of interest to declare.

\section{Acknowledgements}

This work was supported by the National Nanotechnology Center (NANOTEC), NSTDA, Ministry of Science and Technology, through its program of Center of Excellence Network, the Thailand Research Fund (Grant no. TRG5880211) and the "KMUTT 55th Anniversary Commemorative Fund". We would like to thank Dr Pisist Kumnorkaew at the National Nanotechnology Center, Thailand for IPCE instrument.

\section{References}

1 A. Hagfeldt, G. Boschloo, L. C. Sun, L. Kloo and H. Pettersson, Chem. Rev., 2010, 110, 6595-6663.

2 F. Bella, C. Gerbaldi, C. Barolo and M. Gratzel, Chem. Soc. Rev., 2015, 44, 3431-3473.

3 A. Shah, P. Torres, R. Tscharner, N. Wyrsch and H. Keppner, Science, 1999, 285, 692-698.

4 M. Gratzel, J. Photochem. Photobiol., C, 2003, 4, 145-153.

5 J. H. Yum, E. Baranoff, S. Wenger, M. K. Nazeeruddin and M. Gratzel, Energy Environ. Sci., 2011, 4, 842-857.

6 B. E. Hardin, H. J. Snaith and M. D. McGehee, Nat. Photonics, 2012, 6, 162-169.

7 M. Gratzel, Acc. Chem. Res., 2009, 42, 1788-1798.

8 J. N. Clifford, E. Martinez-Ferrero, A. Viterisi and E. Palomares, Chem. Soc. Rev., 2011, 40, 1635-1646.

9 Y. Z. Wu and W. H. Zhu, Chem. Soc. Rev., 2013, 42, 20392058.

10 C. P. Lee, R. Y. Y. Lin, L. Y. Lin, C. T. Li, T. C. Chu, S. S. Sun, J. T. Lin and K. C. Ho, RSC Adv., 2015, 5, 23810-23825.

11 J. Y. Wang, K. Liu, L. C. Ma and X. W. Zhan, Chem. Rev., 2016, 116, 14675-14725.

12 D. P. Hagberg, J. H. Yum, H. Lee, F. De Angelis, T. Marinado, K. M. Karlsson, R. Humphry-Baker, L. C. Sun, A. Hagfeldt, M. Gratzel and M. K. Nazeeruddin, J. Am. Chem. Soc., 2008, 130, 6259-6266.

13 J. F. Huang, J. M. Liu, L. L. Tan, Y. F. Chen, Y. Shen, L. M. Xiao, D. B. Kuang and C. Y. Su, Dyes Pigm., 2015, 114, 18-23.
14 A. Burke, L. Schmidt-Mende, S. Ito and M. Gratzel, Chem. Commun., 2007, 234-236.

15 C. J. Qin, Y. Numata, S. F. Zhang, X. D. Yang, A. Islam, K. Zhang, H. Chen and L. Y. Han, Adv. Funct. Mater., 2014, 24, 3059-3066.

16 S. P. Singh and T. Gayathri, Eur. J. Org. Chem., 2014, 46894707.

17 C. J. Jiao, N. N. Zu, K. W. Huang, P. Wang and J. S. Wu, Org. Lett., 2011, 13, 3652-3655.

18 E. M. Barea, J. Ortiz, F. J. Paya, F. Fernandez-Lazaro, F. Fabregat-Santiago, A. Sastre-Santos and J. Bisquert, Energy Environ. Sci., 2010, 3, 1985-1994.

19 M. D. Ye, X. R. Wen, M. Y. Wang, J. Iocozzia, N. Zhang, C. J. Lin and Z. Q. Lin, Mater. Today, 2015, 18, 155-162.

20 C. J. Qin, Y. Numata, S. F. Zhang, A. Islam, X. D. Yang, K. Sodeyama, Y. Tateyama and L. Y. Han, Adv. Funct. Mater., 2013, 23, 3782-3789.

21 S. Chang, H. D. Wang, L. T. L. Lee, S. Z. Zheng, Q. Li, K. Y. Wong, W. K. Wong, X. J. Zhu, W. Y. Wong, X. D. Xiao and T. Chen, J. Mater. Chem. C, 2014, 2, 3521-3526.

22 L. H. Dong, Z. W. Zheng, Y. F. Wang, X. Li, J. L. Hua and A. G. Hu, J. Mater. Chem. A, 2015, 3, 11607-11614.

23 A. Bessette and G. S. Hanan, Chem. Soc. Rev., 2014, 43, 33423405.

24 M. Mao, J. B. Wang, Z. F. Xiao, S. Y. Dai and Q. H. Song, Dyes Pigm., 2012, 94, 224-232.

25 S. Erten-Ela, M. D. Yilmaz, B. Icli, Y. Dede, S. Icli and E. U. Akkaya, Org. Lett., 2008, 10, 3299-3302.

26 H. Cheema, R. Younts, B. Gautam, K. Gundogdu and A. ElShafei, Mater. Chem. Phys., 2016, 184, 57-63.

27 I. Gonzalez-Valls, A. Mirloup, T. Le Bahers, N. Keller, T. Cottineau, P. Sautet and V. Keller, RSC Adv., 2016, 6, 91529-91540.

28 N. Kaneza, J. T. Zhang, H. Y. Liu, P. S. Archana, Z. C. Shan, M. Vasiliu, S. H. Polansky, D. A. Dixon, R. E. Adams, R. H. Schmehl, A. Gupta and S. L. Pan, J. Phys. Chem. C, 2016, 120, 9068-9080.

29 M. E. El-Khouly, S. Fukuzumi and F. D'Souza, ChemPhysChem, 2014, 15, 30-47.

30 A. Loudet and K. Burgess, Chem. Rev., 2007, 107, 4891-4932.

31 H. Lu, J. Mack, Y. C. Yang and Z. Shen, Chem. Soc. Rev., 2014, 43, 4778-4823.

32 F. D'Souza, A. N. Amin, M. E. El-Khouly, N. K. Subbaiyan, M. E. Zandler and S. Fukuzumi, J. Am. Chem. Soc., 2012, 134, 654-664.

33 M. E. El-Khouly, A. N. Amin, M. E. Zandler, S. Fukuzumi and F. D'Souza, Chem.-Eur. J., 2012, 18, 5239-5247.

34 S. Wanwong, P. Surawatanawong, S. Khumsubdee, S. Kanchanakungwankul and J. Wootthikanokkhan, Heteroat. Chem., 2016, 27, 306-315.

35 J. Zhang, F. T. Lu, S. B. Qi, Y. M. Zhao, K. P. Wang, B. Zhang and Y. Q. Feng, Dyes Pigm., 2016, 128, 296-303.

36 K. Yuwawech, J. Wootthikanokkhan, S. Wanwong and S. Tanpichai, J. Appl. Polym. Sci., 2017, 130, 45010.

37 E. Dell'Orto, L. Raimondo, A. Sassella and A. Abbotto, J. Mater. Chem., 2012, 22, 11364-11369. 
38 G. H. Rao, A. Venkateswararao, L. Giribabu, L. Han, I. Bedja, R. K. Gupta, A. Islam and S. P. Singh, Phys. Chem. Chem. Phys., 2016, 18, 14279-14285.

39 C. M. Cardona, W. Li, A. E. Kaifer, D. Stockdale and G. C. Bazan, Adv. Mater., 2011, 23, 2367-2371.

40 M. K. Nazeeruddin, R. Humphry-Baker, P. Liska and M. Gratzel, J. Phys. Chem. B, 2003, 107, 8981-8987.

41 G. B. Deacon and R. J. Phillips, Coord. Chem. Rev., 1980, 33, 227-250.

42 J. Singh, A. Gusain, V. Saxena, A. K. Chauhan, P. Veerender, S. P. Koiry, P. Jha, A. Jain, D. K. Aswal and S. K. Gupta, J. Phys. Chem. C, 2013, 117, 21096-21104.
43 E. M. J. Johansson, M. Hedlund, H. Siegbahn and H. Rensmo, J. Phys. Chem. B, 2005, 109, 22256-22263.

44 M. Mao and Q. H. Song, Chem. Rec., 2016, 16, 719-733.

45 A. Mishra, M. K. R. Fischer and P. Bauerle, Angew. Chem., Int. Ed., 2009, 48, 2474-2499.

46 H. P. Lu, C. Y. Tsai, W. N. Yen, C. P. Hsieh, C. W. Lee, C. Y. Yeh and E. W. G. Diau, J. Phys. Chem. C, 2009, 113, 20990-20997.

47 O. O. Ogunsolu, I. A. Murphy, J. C. Wang, A. Das and K. Hanson, ACS Appl. Mater. Interfaces, 2016, 8, 28633-28640.

48 L. G. Wei, Y. L. Yang, R. Q. Fan, Y. Na, P. Wang, Y. W. Dong, B. Yang and W. W. Cao, Dalton Trans., 2014, 43, 1136111370. 